\title{
The Late mangos: Is There Any Doubt Humans Are Inducing Climate Change?
}

\author{
Fernando Goulart* and Frédéric Mertens \\ Centro de Desenvolvimento Sustentável, Universidade de Brasília, Brazil
}

Received: December 15, 2017; Published: December 20, 2017

*Corresponding author: Fernando Goulart, Centro de Desenvolvimento Sustentável, Universidade de Brasília, Brazil

\section{Opinion}

We are in the city of Belo Horizonte, Southeastern Brazil, and it is December, but unexpectedly, mango fruits (Mangifera indica) have not yet ripened. As far as we are concerned, we have never experienced a year in which November and December came along without mango fruits ripening in this region. Although native to the Philippines and India, mangos today are a staple and important cultural element in the entire tropical region. Most humans, as well as other animals, above all birds, such as parrots, macaws, and parakeets, appreciate this juicy and fleshy fruit [1]. Mango production depends on climatic stability, and extreme temperatures (above $36^{\circ} \mathrm{C}$ or below $10^{\circ} \mathrm{C}$ ) can delay fruit development Centro de Producoes Tecnicas [2] (accessed December 3, 2017). Mango trees, which are adapted to warm and rainy weather, also need a marked dry season to reach their optimum production, and therefore, in very rainy regions, fruit development is delayed. The weather in Belo Horizonte during the year of 2017 was rather unusual, not to say very strange. It was the coldest winter in the city since 1975 (Instituto de Metereologia), and there was also some rainfall in this period, which is highly uncommon. This could have been the reason behind the mangos taking so long to ripen, since all of these climatic aspects reduce and slow down fruit ripening and production.

Springtime without mangos reminds us of a few things:

I. Climate is already changing, partially due to anthropogenic activities;

II. As a chaotic system, climate and its changes are nonlinear, which explains why Belo Horizonte experienced its coldest winter in times of global warming;

III. Climate changes naturally and has displayed chaotic behavior long before humans ever existed, nevertheless, not acknowledging the links between human activity and climate change acceleration and intensification is unwise, and may hinder efforts for mitigating and possibly reversing such premature climate change.

Over the last decade, there has been an unusual increase in extreme weather events, such as heat waves and precipitation [3].
NASA(National Aeronautics and Space Agency) and NOAA(National Oceanic and Space Agency) data show 2016 as being the warmest year on record. The World Meteorological Organization, a panel of international climate experts, reported that, in 2016, the earth's temperature was $1.1^{\circ} \mathrm{C}$ higher than in the pre-industrial age, glaciers were about 4 million square kilometers smaller than average, and there was a significant rise in sea level, as well as unusual severe droughts and floods [4]. Additionally, global ocean heat was the second highest on record in 2016, contributing to coral bleaching and mortality in tropical waters. In many places, such as California [5] 2017 was the hottest year on record, which explains why Los Angeles is burning in forest and city fires at the very moment these words are being written. However, if the earth's surface is becoming warmer and dryer, why did Belo Horizonte experience its unusually cold and rainy winter? The climate-warming concept is adequate at larger scales. Increasing overall temperature, as opposed to regular linear warming, may lead to more unpredictable patterns. This could result in both hotter and dryer weather, as well as colder more humid weather, such as Belo Horizonte's unusual cold and rainy winter in 2017.

According to the Brazilian National Institute of Meteorology [6] from September to November 2017, the mean temperature anomaly was $+3^{\circ} \mathrm{C}$ in the northern regions of the country and $-2^{\circ} \mathrm{C}$ in some of the southeastern regions. Technically, the weather has always been strange. Nevertheless, this does not discard the fact that humans are intensifying and accelerating climatic variations. The idea of chaos and "strange attractors" were born in meteorological studies with Robert Lorenz [7]. As pointed out by Lorenz, climate is a complex deterministic nonlinear system with cyclical patterns that show temporary stability. The flap of a butterfly's wings in Brazil could set off a Tornado in Texas... the so-called butterfly effect. According to the World Bank database, in 1961, when global atmospheric measurements started, the world emitted three million kilotons of $\mathrm{CO}_{2}$, while in 2014, this concentration increased to twelve million kilotons. Emissions of methane, another greenhouse gas, have increased from 5.3 million kilotons (equivalent in $\mathrm{CO}_{2}$ ) in 1970 to 8 million in 2012. All of these gases have been increasingly accumulating in the atmosphere. As 
a consequence of these multiple emissions, the atmosphere has suffered significant changes over the last century, and especially over the last few decades.

Pre-industrial levels of carbon dioxide in the atmosphere varied from 260 to $290 \mathrm{ppm}$ (parts per million). In 1958 this value was of $315 \mathrm{ppm}$, increasing to $410 \mathrm{ppm}$ in 2017, a concentration unseen since 50 million years ago [8], Methane and Nitrogen gas have increased by $8 \%$ and $90 \%$, respectively, from the 1600 s to the late 1980s [9]. According to the United States Environmental Protection Agency [10], current concentrations of $\mathrm{CO}_{2}, \mathrm{NH}_{4}$, and $\mathrm{N}_{2}$ are unprecedented when compared with the past 800,000 years. Nitrogen gas $\left(\mathrm{N}_{2}\right)$, the dominant ozone-depleting gas emitted by human [11], increased from $280 \mathrm{ppb}$ in the last 800,000 years to $328 \mathrm{ppb}$ in 2015 [10]. $\mathrm{N}_{2}$ is produced mainly through the fertilization of intensive agricultural systems. Finally, considering the well-known relation between these gases and the mean temperature of the planet [12], there is no doubt humans are significantly accelerating and intensifying background and natural climate change. Furthermore, major scientific agencies and specialist panels agree that humans are significantly contributing to climate change, such as the Intergovernmental Panel on Climate Change, the International Assessment of Agricultural Knowledge, Science and Technology for Development, NASA, Scripps Institution of Oceanography, among others.

Such human-induced climate change is declining animal and plant population, such as the golden and harlequin toads $[13,14]$. In order to deal with climate change, species will have to suffer large distribution shifts towards adequate areas [15]. Many of them are predicted to go extinct before the end of the century due to these changes. Climate change is also changing people's lives. Food production will fall due to climate change, especially in the already poor and food-insecure regions [16]. According to the Food and Agriculture Organization, after steadily declining for over a decade, global hunger appears to be on the rise again [17], and climate may be contributing to this increase. Despite the consistency of the evidence showing that humans are changing climate locally and globally, $3 \%$ of the scientific community doubt humans are inducing climate change, while the other $97 \%$ are quite convinced of the opposite. These few "skeptics" are getting more vocal, and policy and decision makers, the general public, and part the mass media are starting to believe that there is not enough evidence to prove humans are inducing climate change.

Some of these scientists are becoming sort of "celebrity skeptics", such as Professor Ricardo Augusto Felício, a Brazilian Antarctic-Climatology specialist who appeared on Jô Soares, a famous talk-show host on Brazilian television, stating humans are not responsible for the climate shift. In the US, same major media TV channels and news agencies support the idea that science is uncertain about the effects of human activity on climate [18].

Among those who deny anthropogenic global warming is Roy Spencer, a well-known climate scientist who is funded by institutions linked to large oil companies [19]. In his book Climate Confusion, Roy Spencer states that small natural changes in the atmospheric conditions can have huge impacts on climate through feedback loops.

For example, he points out that a very little decrease in oceanic cloudiness will let in more light, warming up the ocean, and leading to increased temperature and humidity. Another argument often used by those who deny anthropogenic global warming involves the natural variations in the earth's weather caused by Milankovitch Cycles. Eccentricity is one of these cycles, and describes the changing shape of the earth's orbit from less to more elliptical, occurring on a cycle of approximately 100 thousand years, causing a greater amount of radiation received at the earth's surface. Another Milankovitch cycle is axial tilt, the inclination of the earth's axis in relation to its plane of orbit around the sun, which occurs approximately every 41 thousand years. All of these aspects affect the earth's climate through glacial and interglacial cycles.

Additionally, most skeptics put forward the fact that climate has always been somewhat unstable, even long before humans ever existed, and therefore, humans cannot be held responsible for these current variations. Although we disagree on Spencer (2010) stating environmentalists are senseless alarmists, we agree that non-linear natural climate dynamics, such as the Milankovitch cycles and the effects of ocean cloudiness, have operated with and without humans. Nevertheless, if these natural and anthropogenic causes are combined, we expect climate to change even faster, leading to more unpredictable extreme events. Is this exactly what we are seeing in 2017? Climate change is inevitable, but human activities have the power to anticipate and intensify these changes. For us, these skeptics' arguments are analogous to saying there is no need for hospitals, as we are all going to die someday.

We should not wait for these $3 \%$ of skeptical scientists to be convinced that climate has changed and will change even more with human interferences, before taking strong climate mitigation actions. Meanwhile, humans will have to prepare and adapt to respond to climatic variations and uncertainties, and so will the macaws, parrots, and parakeets, which depend on a large amount of sweet fruits, such as mangos, to reproduce and take good care of the nestlings during this time of year.

\section{Acknowledgement}

We thank the CAPES/PNPD program and the Center for Sustainable Development of the University of Brasilia (Centro de Desenvolvimento Sustentável - Universidade de Brasília) for conceiving the postdoctoral fellowship for FFG. We thank Houssam Zahreddine for the text review.

\section{References}

1. Goulart FF, Vandermeer J, Perfecto I, da Matta-Machado RP (2011) Frugivory by five bird species in agroforest home gardens of Pontal do Paranapanema, Brazil. Agrofor Syst 82: 239.

2. Development Centro de Producoes Tecnicas (2017) Accessed on December 3rd 2017.

3. Coumou D, Rahmstorf S (2012) A decade of weather extremes. Nat Clim Change 2: 491-496. 
4. World Metrological Organization.

5. National Weather Service.

6. Instituto Nacional de Meteorologia.

7. Lorenz E (1972) Predictability: does the flap of a butterfly's wing in Brazil set off a tornado in Texas? na.

8. Scripps Institute of Oceanography.

9. Pearman GI, Etheridge D, De Silva F, Fraser PJ (1986) Evidence of changing concentrations of atmospheric $\mathrm{CO} 2, \mathrm{~N} 2 \mathrm{O}$ and $\mathrm{CH} 4$ from air bubbles in Antarctic ice. Nature 320: 248-250.

10. United States Environmental Protection Agency.

11. Ravishankara AR, Daniel JS, Portmann RW (2009) Nitrous oxide (N20): the dominant ozone-depleting substance emitted in the 21st century. science 326: 123-125.

12. Shakun JD, Clark PU, He F, Marcott SA, Mix AC, et al. (2012) Global warming preceded by increasing carbon dioxide concentrations during the last deglaciation. Nature 484: 49-54.
13. Carey C, Alexander MA (2003) Climate change and amphibian declines: is there a link? Divers Distrib 9: 111-121.

14. Pounds JA, Crump ML (1994) Amphibian declines and climate disturbance: the case of the golden toad and the harlequin frog. Conserv Biol 8: 72-85.

15. Pearson RG, Dawson TP (2003) Predicting the impacts of climate change on the distribution of species: are bioclimate envelope models useful ? Glob Ecol Biogeogr 12: 361-371.

16. Parry M, Rosenzweig C, Iglesias A, Fischer G, Livermore M (1999) Climate change and world food security: a new assessment. Glob Environ Change 9: S51-S67.

17. Food and Agriculture Organization of United Nations.

18. Antilla L (2005) Climate of scepticism: US newspaper coverage of the science of climate change. Glob Environ Change 15: 338-352.

19. The Gaurdian. These are the best arguments from the 3\% of climate scientist 'skeptics.' Really.

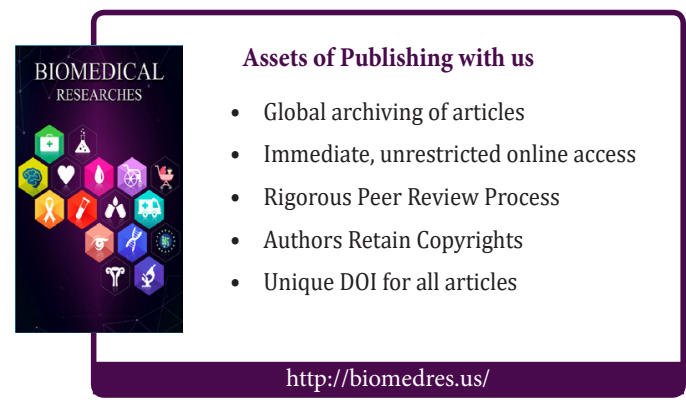

